\title{
Serum Levels of Lipopolysaccharides and Risk of Advanced Colorectal Adenoma
}

\author{
Ellie Chen ${ }^{1}$, Anisha Kalavar ${ }^{1}$, Ngoc-Anh Bui-Thanh ${ }^{1,2}$, Antone R. Opekun ${ }^{1,3,4}$, \\ Donna L. White ${ }^{1,3,4,5,6}$, Daniel Rosen 7 , David Y. Graham ${ }^{1,3,4}$, \\ Rolando E. Rumbaut ${ }^{1,2}$, Hashem B. El-Serag ${ }^{1,3,4,5,6}$ and Li Jiao ${ }^{1,3,4,5,6^{*}}$ \\ ${ }^{1}$ Department of Medicine, Baylor College of Medicine, Houston, TX, USA; ${ }^{2}$ Center for Translational Research on Inflammatory Diseases \\ (CTRID), Michael E. DeBakey VA Medical Center, Houston, TX, USA; ${ }^{3}$ Section of Gastroenterology and Hepatology, Michael E. DeBakey \\ VA Medical Center, Houston, TX, USA; ${ }^{4}$ Texas Medical Center Digestive Disease Center, Houston, TX, USA; ${ }^{5}$ Center for Innovations in \\ Quality, Effectiveness and Safety (IQuESt), Michael E. DeBakey VA Medical Center, Houston, TX, USA; ${ }^{6}$ Dan L Duncan Cancer Center, \\ Baylor College of Medicine, Houston, TX, USA; ${ }^{7}$ Section of Pathology and Immunology, Michael E. DeBakey VA Medical Center,
} Houston, TX, USA

\begin{abstract}
Background and objectives: Production of lipopolysaccharides (LPS) from the outer membrane of Gram-negative bacteria promotes the survival of cancer cells. Systemic level of LPS is considered a biomarker for microbial translocation. The association between LPS and the risk of colorectal tumors is not well known. The goal of this study was to examine the association between LPS serum levels and risk of advanced colorectal adenoma (ACA).

Methods: In this colonoscopy clinic-based case-control study, cases were male patients with a diagnosis of ACA, and controls were polyp-free male participants. Cases and controls were individually matched by age, ethnicity, and blood collection time. Information on demographics, lifestyle, and medical history was obtained using structured questionnaires. Serum levels of LPS were quantitated using the kinetic limulus amebocyte lysate assay. Multivariable conditional logistic regression model was used to estimate the odds ratio and its $95 \%$ confidence interval of the ACA in association with serum LPS adjusting for cigarette smoking, body mass index, and medical history.
\end{abstract}

Results: We examined 43 cases and 43 paired controls, with a mean age of 62 years. There was no significant difference in serum LPS levels between the cases and controls $(0.28$ vs. 0.25 endotoxin units $(E U) / m L, P=0.58$ for the non-parametric test). The adjusted odds ratio and its 95\% confidence interval of ACA was $1.83(0.40-8.24)$ in multivariable logistic regression model.

Conclusions: Serum levels of LPS were not statistically significantly associated with an increased risk of ACA in this preliminary study.

Keywords: Gut microbiome; Colorectal cancer; LPS; Endotoxin, Leaky gut; Microbial translocation; Biomarker.

Abbreviations: ACA, advanced colorectal adenoma; BMI, body mass index; CI, confidence interval; $\mathrm{CRC}$, colorectal cancer; $\mathrm{CV}$, coefficient of variation; $\mathrm{EU}$, endotoxin units; LAL, limulus amebocyte lysate; LPS, lipopolysaccharides; MEDVAMC, Michael E. DeBakey VA Medical Center; MET, metabolic equivalent of task; OR, odds ratio; TLR, toll-like receptor.

Received: January 01, 2020; Revised: February 21, 2020; Accepted: February 22, 2020

${ }^{*}$ Correspondence to: Li Jiao, Center for Innovations in Quality, Effectiveness and Safety (IQuESt), Michael E DeBakey VA Medical Center. 2002 Holcombe Blvd, MS152, Houston 77030, Texas, USA. Tel: 713-440-4456, Fax: 713-748-7359, E-mail: jiao@bcm.edu

How to cite this article: Chen E, Kalavar A, Bui-Thanh N-A, Opekun AR, White DL, Rosen D, Graham DY, Rumbaut RE, El-Serag HB, Jiao L. Serum Levels of Lipopolysaccharides and Risk of Advanced Colorectal Adenoma. Exploratory Research and Hypothesis in Medicine 2020;5(2):47-52. doi: 10.14218/ERHM.2020.00001.
Introduction

The gastrointestinal tract is the habitat of numerous bacteria of which some are known pathogens, including $B$. fragilis, Clostridium, and certain strains of Escherichia coli. The microbiome has multiple functions in metabolism, mucosal integrity, and immunity. ${ }^{1}$ Prior studies have shown that an imbalance of the gut microbiome and the microbial metabolites can trigger dysregulation of various metabolic pathways that lead to colon cancer. ${ }^{2-5}$ For example, the Gram-negative anaerobic bacteria, Fusobacterium, are more abundant in colorectal cancer (CRC) tissue. Fusobacterium nucleatum creates an inflammatory environment that promotes the formation of colorectal tumors. ${ }^{6}$ Similarly, Escherichia coli cause genotoxic inflammation by attaching to the gut epithelium. $.^{7,8} \mathrm{Sev}-$ 
eral mediators for these oncogenic effects of the bacteria have been proposed. One of which is through lipopolysaccharides (LPS), which directly induce deleterious alterations of enterocyte membrane structure and function.

LPS, also referred to as endotoxins, are found in the outer membrane of Gram-negative bacteria. When Gram-negative bacteria undergo cell death or cell division, the bacterial membranes release LPS. Microbial translocation is defined as the passage of viable or non-viable microbes and microbial product such as LPS across an anatomically intact intestinal barrier to lamina propria and mesenteric lymph node, and possibly other tissue. ${ }^{9}$ The continuous presence of these products in the systemic circulation may lead to low-grade inflammation. As inflammation ensues, macromolecular LPS can be absorbed and frequently induce a toxic reaction by various receptor-mediated signals. ${ }^{10}$ Elevated LPS levels have been associated with induction of tumor necrosis factor alpha, leading to chronic inflammation and a weakened intestinal epithelial barrier, ${ }^{11}$ and appear to be pathogenic factors in disorders such as irritable bowel disease and necrotizing enterocolitis. ${ }^{12,13}$ Animal studies have also shown that LPS may accelerate inflammation-related aging. ${ }^{14}$ Therefore, systemic levels of LPS may be a biomarker of microbial translocation and colorectal adenomas or CRC.

While several studies have examined the association between serum levels of LPS or markers of microbial translocation and risk of developing CRC, ${ }^{15,16}$ few have studied the association between LPS and its precursor lesion, namely advanced colorectal adenoma (ACA). ${ }^{17-19}$ Adenomas are the products of proliferation from dysplastic nonmalignant epithelial cells, which can progress into adenocarcinoma as deleterious mutations accumulate.

Therefore, we examined the association between serum levels of LPS and risk of developing ACA in a colonoscopy clinic-based case-control study using a kinetic assay. We hypothesized that serum levels of LPS are associated with an increased risk of ACA.

\section{Methods}

\section{Study design and study population}

The study cohort and comprehensive eligibility and exclusion criteria for this cross-sectional study have been previously reported. ${ }^{20}$ The study was approved by the Institutional Review Boards of Baylor College of Medicine and Michael E. DeBakey VA Medical Center (MEDVAMC). All participants provided written informed consent for the study.

From 2013 to 2017, a total of 612 participants, aged 50 and 79 years, were recruited from the colonoscopy clinic at the MEDVAMC. A total of 55 patients had a diagnosis of ACA, which was defined as a polyp $>1 \mathrm{~cm}$ found on colonoscopy or a colorectal adenoma with a villous component or high-grade dysplasia pathologically. Participants in the control group had no colorectal polyps found during the colonoscopy and had no history of colorectal adenoma in the past 3 years. Each control was individually matched to each case according to age ( \pm 5 years), race/ethnicity, and sample collection time ( \pm 3 months; and morning or afternoon collection).

\section{Data collection}

Patients were enrolled either on the day they were educated for bowel preparation or on the day of their colonoscopy. Information on demographics, lifestyle, and medical history was obtained through an interviewer-administered lifestyle questionnaire. The detailed procedure has been previously reported. ${ }^{20}$ The pathologist (Dr. Daniel Rosen) obtained the pathological features of the adenoma/polyp. The number of polyps/adenoma, location and size of the lesion, hyperplastic polyps, and high-grade dysplasia were documented for each patient.

\section{Blood collection and LPS measurement}

Fasting blood samples were collected on the day of the colonoscopy. Serum used for the LPS assay was placed into $7 \mathrm{~mL}$ anticoagulant-free BD vacutainer glass tubes previously baked to eliminate possible LPS contamination, and aliquoted into an endotoxin-free glass vial that was baked. These samples were stored at $-80{ }^{\circ} \mathrm{C}$ before testing for LPS using the quantitative Limulus Amebocyte Lysate (LAL) assay. The PYROGENT-5000 kinetic turbidimetric LAL assay (Lonza, Basel, Switzerland) is designed to test for endotoxin of Gram-negative bacteria in serum. The serum samples were diluted to a 1:10 ratio, heated, mixed with the LAL, and incubated for $10 \mathrm{~m}$ at $37{ }^{\circ} \mathrm{C}$, and a stop reagent was added to stop the reaction. A substrate solution was mixed with LAL solution and incubated at the same temperature for $6 \mathrm{~m}$. A yellow color appeared if the endotoxin was present in the serum. The absorbance of the sample was measured through a spectrophotometer at wavelength of $340 \mathrm{~nm}$. These absorbance values were then converted to concentrations in EU/mL and reported. The sensitivity of the assay ranges from 0.01 to $100 \mathrm{EU} / \mathrm{mL}$. One EU is defined as the biological activity induced in the endotoxin test by about $120 \mathrm{pg}$ LPS from E. coli $\mathrm{O} 113 \mathrm{H} 10: \mathrm{K}^{21}$

\section{Quality control}

The matched case-control pairs were assayed in the same 96-well plate. Each sample was assayed in duplicate. We included $5 \%$ of duplicate samples in each batch to monitor the batch variation. After examining the duplicate data, we found 11 case-control pairs (of 55 cases-control pairs) had a high $(>15 \%)$ coefficient of variation $(\mathrm{CV})$ in either the case or control. These pairs were not included in the final analysis. We also eliminated one outlier of LPS value in controls. Therefore, we included 43 case-control pairs in the final analysis.

\section{Statistical analysis}

Data were analyzed using the STATA (StataCorp, College Station, TX, USA) software. The chi-squared test was used to test the difference in the distribution of categorical data between cases and controls. The paired $t$-test was used to test the difference in the means of continuous characteristics (e.g., body mass index [BMI] and physical activity) between cases and controls. We used the Wilcoxon signed-rank test to compare the means of LPS levels between cases and controls, because the LPS levels did not follow the normal distribution as tested by the Kolmogorov-Smirnov test. The natural log-transformed LPS values were generated for the analyses where the normal distribution assumption should be met. We examined the associated between covariates and normalized LPS levels using the linear regression. Univariate and multivariable conditional logistic regression were used to estimate the odds ratio (OR) and $95 \%$ confidence interval (CI) for ACA in association with the transformed LPS value as the continuous variable. The covariates in the multivariable regression model included smoking, alcohol use, BMI, hypertension, and type 2 diabetes. We 
Table 1. Characteristics of controls without polyps and cases with advanced colorectal adenomas

\begin{tabular}{|c|c|c|c|}
\hline Characteristics Mean (standard deviation) or \% & Controls $(n=43)$ & Cases $(n=43)$ & $P$-value \\
\hline Age (years) & $62.9(6.7)$ & $61.9(6.4)$ & 0.43 \\
\hline Men, \% & 100 & 100 & 1.00 \\
\hline Non-Hispanic white, \% & 62.0 & 60.4 & 0.35 \\
\hline $\mathrm{BMI}, \mathrm{kg} / \mathrm{m}^{2}$ & $29.9(5.5)$ & $31.6(8.8)$ & 0.37 \\
\hline $\mathrm{BMI}$ in categories, $\mathrm{kg} / \mathrm{m}^{2}, \%$ & & & 0.67 \\
\hline$<25$ & 25.58 & 18.60 & \\
\hline $25-<30$ & 25.58 & 27.91 & \\
\hline$\geq 30$ & 48.84 & 53.49 & \\
\hline Smoking status, \% & & & 0.09 \\
\hline Never & 44.2 & 23.2 & \\
\hline Former & 37.2 & 44.2 & \\
\hline Current & 18.6 & 32.6 & \\
\hline Current alcohol drinking, \% & 53.5 & 60.5 & 0.56 \\
\hline History of polyp, \% & 18.6 & 20.9 & 0.79 \\
\hline \multicolumn{4}{|l|}{ Physical activity, MET-minutes per week } \\
\hline Median (interquartile range) & $876(198-3,066)$ & $738(169-3,066)$ & 0.82 \\
\hline Type 2 diabetes, \% & 37.2 & 25.6 & 0.24 \\
\hline Hypertension, \% & 55.8 & 62.8 & 0.51 \\
\hline \multicolumn{4}{|l|}{ Lipopolysaccharide (EU/mL) } \\
\hline Median (interquartile range) & $0.24(0.19-0.31)$ & $0.24(0.18-0.35)$ & 0.58 \\
\hline Mean (standard deviation) & $0.26(0.01)$ & $0.28(0.02)$ & 0.23 \\
\hline \multicolumn{4}{|l|}{ Pathology of adenoma (median (range) or \%) } \\
\hline No. of adenoma & & $2(1-6)$ & \\
\hline Size of largest adenoma if multiple $(\mathrm{cm})$ & & $1.2(0.5-3.5)$ & \\
\hline Having high-grade dysplasia, \% & & 23.3 & \\
\hline Having villous component, \% & & 37.0 & \\
\hline Serrated adenoma, \% & & 5.0 & \\
\hline
\end{tabular}

BMI, body mass index; EU, endotoxin unit; LPS, lipopolysaccharides; MET, metabolic equivalent of task.

also modeled the LPS levels as a dichotomized variable using the median in the controls as the cutoff point. Among those who had adenoma, we further tested whether transformed LPS levels differ by the characteristics of ACA according to the number of adenoma (more than 2 ACA or not), size of the adenoma $(<2 \mathrm{~cm} v s . \geq 2 \mathrm{~cm}$ ), villous component (have vs. not have), and dysplasia (high grade dysplasia present or not). A $P$-value $<0.05$ indicated statistical significance in a two-sided test.

\section{Results}

All participants were men with a mean age of 62 years. There was no significant difference in the distribution of BMI, history of polyps, physical activity, history of diabetes and hypertension, or alcohol use between 43 cases and 43 controls (Table 1). There was an insignificantly higher proportion of current smokers in the cases than controls $(P=0.09)$. Among those who were found to have adenoma, $67 \%$ had one to two lesions, $19 \%$ had three to four lesions, and $14 \%$ had more than four lesions. A total of $29 \%$ had the size of adenoma greater than $2 \mathrm{~cm}, 37 \%$ adenoma had villous components, and $23 \%$ had high-grade dysplasia.

LPS was detected in all our samples. The absolute levels of LPS were slightly higher in cases $(0.28 \mathrm{EU} / \mathrm{mL})$ than controls $(0.25 \mathrm{EU} /$ $\mathrm{mL})(P=0.23)$ (Table 1). Figure 1 shows the pairwise comparison between the individually matched cases and controls using the untransformed value. Furthermore, the serum levels of LPS did not differ by smoking, alcohol use, and BMI in controls $(P>0.05)$ (data not shown). There was no statistically significant association between LPS and the risk of ACA (multivariable $\mathrm{OR}=1.83$, $95 \%$ CI: 0.40 to 8.24 ) (Table 2). We did not observe a significant association when LPS was modeled as a dichotomized variable (data not shown).

We further examined the LPS levels based on the characteristics of adenoma among patients with ACA (Fig. 2). Patients with a large sized adenoma $(>2 \mathrm{~cm})$, villous adenoma, or high-grade dysplasia 


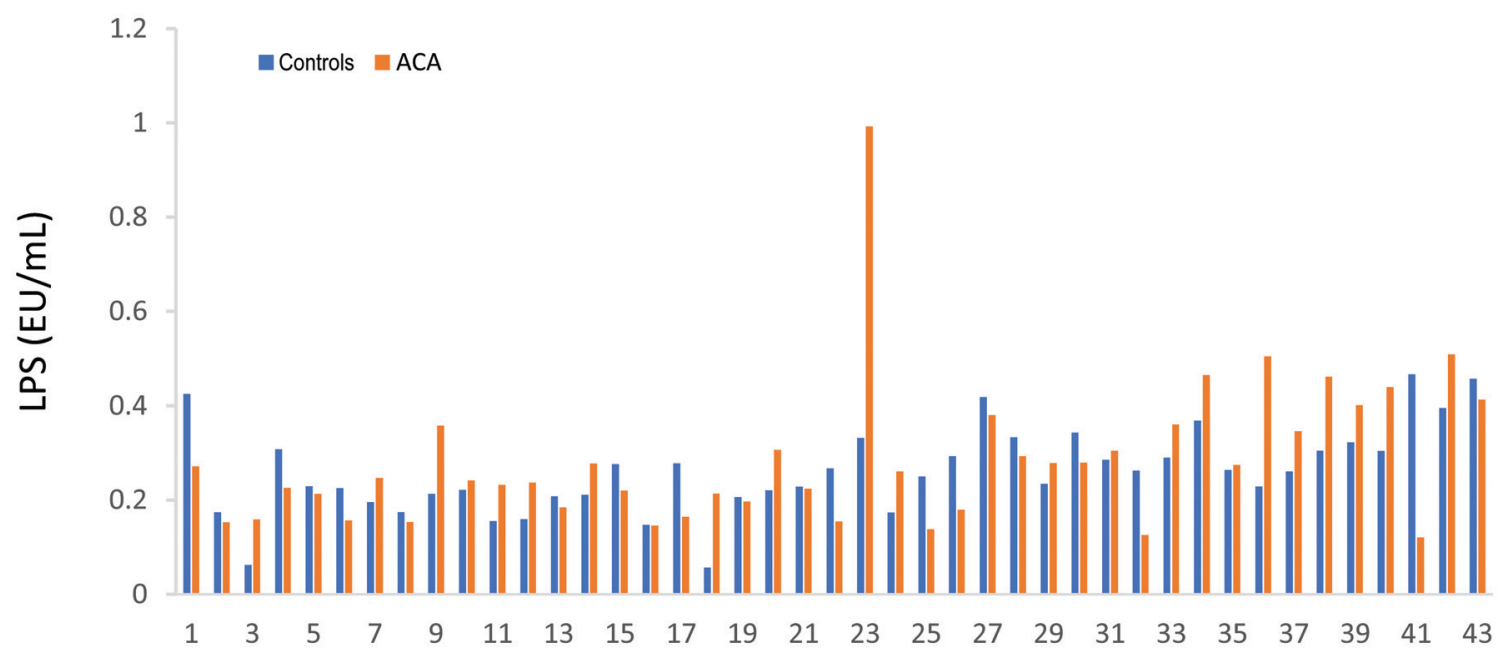

Fig. 1. Serum levels of LPS in $\mathbf{4 3}$ advanced colorectal adenoma cases and $\mathbf{4 3}$ polyp-free controls.

tended to have higher serum levels of LPS compared to patients with smaller, tubular adenoma, and adenoma without high-grade dysplasia, respectively $(P \leq 0.10)$. However, the LPS levels did not differ by the number of adenoma $(P=0.57$, data not shown).

\section{Discussion}

This small-scale case-control study showed that LPS levels were slightly higher in cases than controls, and slightly higher in ACA that was larger, with villous component, or with high-grade dysplasia than the small or tubular ACA. However, there was no statistically significant association between LPS and the risk of ACA. Larger studies are warranted to further investigate the association between the systemic levels of LPS and risk of colorectal tumors and understand the relevant clinical implications.

It is biologically plausible that LPS can contribute to colorectal carcinogenesis. LPS is classified as a pathogen-associated molecular pattern, which is recognized by pattern recognition receptors, such as toll-like receptors (TLRs), on enterocytes or other immune cells. ${ }^{22}$ LPS enter the intestinal capillaries after the death of Gram-negative bacteria in the gut. ${ }^{23}$ An animal study showed that an increase in physiological concentrations of LPS led to increased permeability at the tight junction in cells. ${ }^{24}$ The increased permeability further caused increased circulating levels of LPS, allowing for further inflammation ${ }^{25}$ because the lipid A components of the LPS structure bound to the TLR-4/cluster of differentiation complex on innate immune cells in the circulation, and trigger the production of inflammatory cytokines. ${ }^{26,27}$ This signaling pathway

Table 2. Univariate and multivariate conditional logistic regression models for advanced colorectal adenomas in association with serum levels of LPS

\begin{tabular}{llll}
\hline & OR & $95 \% \mathrm{Cl}$ & $\boldsymbol{P}$-value \\
\hline \multirow{3}{*}{ LPS } & Univariate & & \\
& 1.88 & $0.56-6.39$ & 0.30 \\
& Multivariate & & \\
LPS & 1.83 & $0.40-8.24$ & 0.43 \\
\hline
\end{tabular}

LPS, lipopolysaccharide; OR, odds ratio; $\mathrm{Cl}$, confidence interval. can lead to immune escape, uncontrolled tumor growth, and increased proliferation/metastasis of colorectal carcinoma. ${ }^{28-30}$

In a European population, a positive association between elevated IgA and IgG anti-LPS immunoglobulins and an increased risk of developing CRC was shown. ${ }^{16}$ Another study of 138 cases and 324 controls found that higher concentrations of LPS as measured by the LAL assay were significantly associated with colorectal tubular adenomas. ${ }^{17}$ A case-control study in Korea, also used the LAL assay, found that 74 patients with colorectal polyps had higher levels of endotoxin than 71 controls $(0.108$ vs. $0.049 \mathrm{EU} / \mathrm{mL}, P<$ 0.001). ${ }^{18}$ However, we did not find a significant difference in the serum levels of LPS between ACA and polyp-free controls. Nevertheless, the LSP levels were higher in ACA cases, in patients harboring larger ACA or highly malignant ACA. Whether LPS can serve as a biomarker for colorectal tumor needs further investigation.

We showed that LPS can be detected in individuals without polyps after controlling for the possibility of endotoxin contamination to the best of our ability. To date, the physiological range of LPS has not been well established in healthy individuals. The clinical significance of systemic LPS is elusive. One study evaluated 38 studies that measured LPS levels in the general population. ${ }^{21}$ Among the 19 studies that reported an LPS level of EU/mL, the median level was $0.32 \mathrm{EU} / \mathrm{mL}$, and the $25-75 \%$ interquartile range was $0.23-3.89$ $\mathrm{EU} / \mathrm{mL}$. The median LPS value in poly-free participants $(0.24 \mathrm{EU} /$ $\mathrm{mL}$ ) was in the range reported by these previous studies. Our study showed that the kinetic LAL assay can be used to test LPS in human serum in an epidemiologic study. The adequate dilution of the samples was critical in obtaining reproducible measurements.

We included obesity, smoking status, and alcohol as the confounding factors in the statistical model because they are known risk factors for CRC. Smoking was also a significant risk factor of ACA in our study. However, we did not observe an association between smoking status and LPS. While cigarettes do contain LPS and increased levels of lipopolysaccharide-binding protein are found in smokers, the association between serum levels of LPS and cigarette smoking is still unclear. ${ }^{31,32}$ Studies have also shown that excessive alcohol intake is significantly associated with elevated levels of serum LPS, ${ }^{33}$ as well as a possible link between obesity and increased serum LPS. ${ }^{34}$ We did not observe the association between serum levels of LPS and these host and environmental factors in our small-scale study.

Our study had several strengths. We used glass vials to store the 

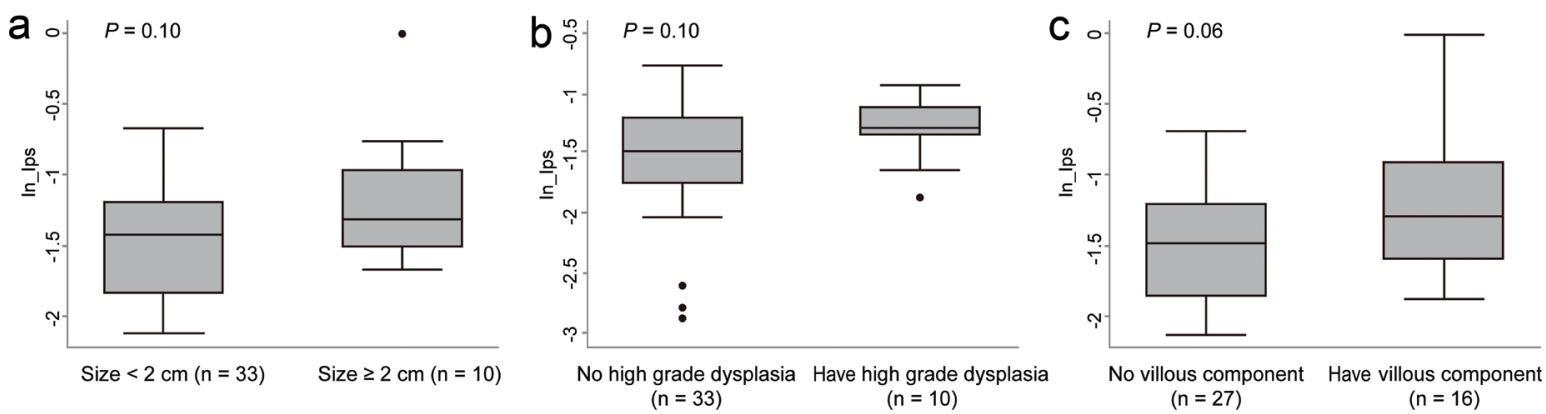

Fig. 2. Box-plot shows the difference in transformed LPS values based on the characteristics of the adenoma. $P$ value was for the Student's $t$-test. Panel A, by adenoma size ( $<2 \mathrm{~cm}$ vs. $\geq 2 \mathrm{~cm}, P=0.10$ ); Panel B, by the degree of dysplasia (no vs. high-grade, $P=0.10$ ); Panel $\mathrm{C}$, by villous component (no vs. have, $P=0.06)$

samples to prevent the possibility of the attachment of LPS to the plastic tubes. The glass vials were baked to prevent the contamination of endotoxin in the environment. We assayed the matched cases and controls in the same experiment batch to avoid the potential batch effect. We used the same lot of assay kit in the analysis to reduce the kit variation. In addition, those samples that had high CV were not included in the final analysis. Participants were excluded if they had a history of cancer, familial adenomatous polyposis, Lynch Syndrome, acute infectious disease, and antibiotic treatment in the past 3 months. Nevertheless, several limitations should be noted. The small sample size (43 paired samples) was the major limitation of the study. A larger sample size would have increased the statistical power of the data analysis. Because we enrolled the study participants from an elective colonoscopy clinic, the pool of the polyp-free controls was relatively small. Lastly, the study population consisted of only male veterans who may not represent women and the general population.

\section{Future directions}

A larger study is needed to determine whether LPS can be used as a biomarker of microbial translocation or leaky gut in populationbased studies on colorectal polyp, benign adenoma, and adenoma with malignant potential. To date, the LPS assay has not been widely used in cancer epidemiologic research. Its clinical value should be explored further. Additional biomarkers can be incorporated to advance our understanding of the inflammatory nature of ACA. Finally, it has been shown that not all the components of LPS stimulate an immune response. Precise detection of the effective component of LPS may have greater clinical relevance. ${ }^{35,36}$

\section{Conclusions}

Taken together, our study moves the field forward by showing that LPS can be detected in the serum of polyps-free individuals. We observed a nonsignificantly positive association between serum levels of LPS and ACA. The association between LPS and the risk of colorectal tumor should be further examined in larger studies using the same research approach established in the present study.

\section{Acknowledgments}

We thank David Ramsey at Baylor College of Medicine for data management and project management. We also thank Ashley Johnson, Liang Chen, Sarah Plew, Ava Smith, Preksha Shah, and Jocelyn Uriostegui for collecting and processing samples. We thank the physicians and nurses at the endoscopy unit of the Michael E. DeBakey VA Medical Center for sample collection and the veterans who participated in this study.

\section{Funding}

Supported by the Cancer Prevention and Research Institute of Texas (RP\#140767, PI: Jiao, L; Petrosino, J), Gillson Longenbaugh Foundation, Golfers Against Cancer organization (PI: Jiao, L). Partly supported by the use of resources and facilities at the Houston VA HSR\&D Center for Innovations in Quality, Effectiveness and Safety (CIN13-413) and The Texas Medical Center Digestive Disease Center (P30 DK56338, PI: El-Serag, HB). Jiao received the salary support from the NIH R01CA172880 (PI: Jiao, L). White receives the Merit Review Award from the U.S. Department of Veterans Affairs (CX001430). Rumbaut received the Merit Review Award I01 BX002551 from the U.S. Department of Veterans Affairs. The opinions expressed are those of the authors and not necessarily those of the Department of Veterans Affairs, the U.S government or Baylor college of Medicine.

\section{Conflict of interest}

The authors have no conflict of interests related to this publication.

\section{Author contributions}

Study concept and design (LJ), acquisition of data (NAB, ARO, DR, DYG, RER, HBE, LJ), analysis and interpretation of data (EC, AK, ARO, DLW, DYG, HBE, LJ), drafting of the manuscript (EC, AK, LJ), critical revision of the manuscript for important intellectual content (ARO, DYG, DLW, HBE), administrative, technical, or material support, study supervision (RER, HBE, LJ).

\section{References}

[1] Jandhyala SM, Talukdar R, Subramanyam C, Vuyyuru H, Sasikala M Nageshwar Reddy D. Role of the normal gut microbiota. World J Gastroenterol 2015;21(29):8787-8803. doi:10.3748/wjg.v21.i29.8787. 
[2] Guertin KA, Li XS, Graubard BI, Albanes D, Weinstein SJ, Goedert $\mathrm{JJ}$, et al. Serum trimethylamine $\mathrm{N}$-oxide, carnitine, choline, and betaine in relation to colorectal cancer risk in the alpha tocopherol, beta carotene cancer prevention study. Cancer Epidemiol Biomarkers Prev 2017;26(6):945-952. doi:10.1158/1055-9965.EPI-160948.

[3] Liesenfeld DB, Habermann N, Toth R, Owen RW, Frei E, Staffa J, et al. Changes in urinary metabolic profiles of colorectal cancer patients enrolled in a prospective cohort study (ColoCare). Metabolomics 2015;11(4):998-1012. doi:10.1007/s11306-014-0758-3.

[4] Louis P, Hold GL, Flint HJ. The gut microbiota, bacterial metabolites and colorectal cancer. Nature reviews. Nat Rev Microbiol 2014;12(10):661-672. doi:10.1038/nrmicro3344.

[5] O'Keefe SJ. Diet, microorganisms and their metabolites, and coIon cancer. Nat Rev Gastroenterol Hepatol 2016;13(12):691-706. doi:10.1038/nrgastro.2016.165.

[6] Kostic AD, Gevers D, Pedamallu CS, Michaud M, Duke F, Earl AM, et al. Genomic analysis identifies association of fusobacterium with colorectal carcinoma. Genome Res 2012;22(2):292-298. doi:10.1101/ gr.126573.111.

[7] Palmela C, Chevarin C, Xu Z, Torres J, Sevrin G, Hirten R, et al. Adherent-invasive Escherichia coli in inflammatory bowel disease. Gut 2018;67(3):574-587. doi:10.1136/gutjnl-2017-314903.

[8] Wassenaar TM. E. Coli and colorectal cancer: a complex relationship that deserves a critical mindset. Crit Rev Microbiol 2018;44(5):619632. doi:10.1080/1040841X.2018.1481013.

[9] Blodget E, Shen C, Aldrovandi G, Rollie A, Gupta SK, Stein JH, et al. Relationship between microbial translocation and endothelial function in hiv infected patients. PLoS One 2012;7(8):e42624. doi:10.1371/ journal.pone.0042624.

[10] Poltorak A, He X, Smirnova I, Liu MY, Van Huffel C, Du X, et al. Defective LPS signaling in $\mathrm{C} 3 \mathrm{H} / \mathrm{HeJ}$ and $\mathrm{C} 57 \mathrm{BL} / 10 \mathrm{ScCr}$ mice: mutations in Tlr4 gene. Science 1998;282(5396):2085-2088. doi:10.1126/science.282.5396.2085.

[11] Guo S, Al-Sadi R, Said HM, Ma TY. Lipopolysaccharide causes an increase in intestinal tight junction permeability in vitro and in vivo by inducing enterocyte membrane expression and localization of TLR-4 and CD14. Am J Pathol 2013;182(2):375-387. doi:10.1016/j. ajpath.2012.10.014.

[12] Gardiner KR, Halliday MI, Barclay GR, Milne L, Brown D, Stephens S, et al. Significance of systemic endotoxaemia in inflammatory bowel disease. Gut 1995;36(6):897-901. doi:10.1136/gut.36.6.897.

[13] Sharma R, Tepas JJ 3rd, Hudak ML, Mollitt DL, Wludyka PS, Teng RJ, et al. Neonatal gut barrier and multiple organ failure: role of endotoxin and proinflammatory cytokines in sepsis and necrotizing enterocolitis. J Pediatr Surg 2007;42(3):454-461. doi:10.1016/j.jpedsurg.2006.10.038.

[14] Kim KA, Jeong JJ, Yoo SY, Kim DH. Gut microbiota lipopolysaccharide accelerates inflamm-aging in mice. BMC Microbiol 2016;16:9. doi:10.1186/s12866-016-0625-7.

[15] Citronberg JS, Wilkens LR, Le Marchand L, Lim U, Monroe KR, Hullar MAJ, et al. Plasma lipopolysaccharide-binding protein and colorectal cancer risk: a nested case-control study in the multiethnic cohort. Cancer Causes Control 2018;29(1):115-123. doi:10.1007/s10552017-0990-z.

[16] Kong SY, Tran HQ, Gewirtz AT, McKeown-Eyssen G, Fedirko V, Romieu $\mathrm{I}$, et al. Serum endotoxins and flagellin and risk of colorectal cancer in the european prospective investigation into cancer and nutrition (EPIC) cohort. Cancer Epidemiol Biomarkers Prev 2016;25(2):291301. doi:10.1158/1055-9965.EPI-15-0798.

[17] Kang M, Edmundson P, Araujo-Perez F, McCoy AN, Galanko J, Keku TO. Association of plasma endotoxin, inflammatory cytokines and risk of colorectal adenomas. BMC cancer 2013;13:91. doi:10.1186/14712407-13-91.

[18] Lee KK, Yum KS. Association of endotoxins and colon polyp: a casecontrol study. J Korean Med Sci 2012;27(9):1062-1065. doi:10.3346/ jkms.2012.27.9.1062.

[19] Yang B, Bostick RM, Tran HQ, Gewirtz AT, Campbell PT, Fedirko V. Circulating biomarkers of gut barrier function: correlates and non- response to calcium supplementation among colon adenoma patients. Cancer Epidemiol Biomarkers Prev 2016;25(2):318-326. doi:10.1158/1055-9965.EPI-15-0488.

[20] Liu Y, Ajami NJ, El-Serag HB, Hair C, Graham DY, White DL, et al. Dietary quality and the colonic mucosa-associated gut microbiome in humans. Am J Clin Nutr 2019;110(3):701-712. doi:10.1093/ajcn/ nqz139.

[21] Gnauck A, Lentle RG, Kruger MC. Chasing a ghost?-issues with the determination of circulating levels of endotoxin in human blood. Crit Rev Clin Lab Sci 2016;53(3):197-215. doi:10.3109/10408363.2015.1 123215.

[22] Park JH, Jeong SY, Choi AJ, Kim SJ. Lipopolysaccharide directly stimulates Th17 differentiation in vitro modulating phosphorylation of RelB and NF-kB1. Immunol Lett 2015;165(1):10-19. doi:10.1016/j. imlet.2015.03.003.

[23] Neal MD, Leaphart C, Levy R, Prince J, Billiar TR, Watkins S, et al. Enterocyte TLR4 mediates phagocytosis and translocation of bacteria across the intestinal barrier. J Immunol 2006;176(5):3070-3079. doi:10.4049/jimmunol.176.5.3070.

[24] Guo S, Al-Sadi R, Said HM, Ma TY. Lipopolysaccharide causes an increase in intestinal tight junction permeability in vitro and in vivo by inducing enterocyte membrane expression and localization of TLR-4 and CD14. Am J Pathol 2013;182(2):375-387. doi:10.1016/j. ajpath.2012.10.014.

[25] Gardiner KR, Halliday MI, Barclay GR, Milne L, Brown D, Stephens S, et al. Significance of systemic endotoxaemia in inflammatory bowel disease. Gut 1995;36(6):897-901. doi:10.1136/gut.36.6.897.

[26] Sweet MJ, Hume DA. Endotoxin signal transduction in macrophages. J Leukoc Biol 1996;60(1):8-26. doi:10.1002/jlb.60.1.8.

[27] Wright SD, Ramos RA, Tobias PS, Ulevitch RJ, Mathison JC. CD14, a receptor for complexes of lipopolysaccharide (LPS) and LPS binding protein. Science 1990;249(4975):1431-1433. doi:10.1126/science.1698311.

[28] O'Leary DP, Bhatt L, Woolley JF, Gough DR, Wang JH, Cotter TG, et al. TLR-4 signalling accelerates colon cancer cell adhesion via NF-kB mediated transcriptional up-regulation of Nox-1. PLoS One 2012;7(10):e44176. doi:10.1371/journal.pone.0044176.

[29] Tang X, Zhu Y. TLR4 signaling promotes immune escape of human colon cancer cells by inducing immunosuppressive cytokines and apoptosis resistance. Oncol Res 2012;20(1):15-24. doi:10.3727/096 $504012 X 13425470196092$

[30] Liu WT, Jing YY, Yan F, Han ZP, Lai FB, Zeng JX, et al. LPS-induced CXCR4-dependent migratory properties and a mesenchymal-like phenotype of colorectal cancer cells. Cell Adh Migr 2017;11(1):13-23. d oi:10.1080/19336918.2015.1134404.

[31] Hasday JD, Bascom R, Costa JJ, Fitzgerald T, Dubin W. Bacterial endotoxin is an active component of cigarette smoke. Chest 1999;115(3):829-835. doi:10.1378/chest.115.3.829.

[32] Gonzalez-Quintela A, Alonso M, Campos J, Vizcaino L, Loidi L, Gude F. Determinants of serum concentrations of lipopolysaccharide-binding protein (LBP) in the adult population. PLoS One 2013;8(1):e54600. doi:10.1371/journal.pone.0054600.

[33] Bala S, Marcos M, Gattu A, Catalano D, Szabo G. Acute binge drinking increases serum endotoxin and bacterial DNA levels in healthy individuals. PLoS One 2014;9(5):e96864. doi:10.1371/journal. pone.0096864.

[34] Trøseid M, Nestvold TK, Rudi K, Thoresen H, Nielsen EW, Lappegård KT. Plasma lipopolysaccharide is closely associated with glycemic control and abdominal obesity: evidence from bariatric surgery. Diabetes Care 2013;36(11):3627-3632. doi:10.2337/dc13-0451.

[35] Jackie J, Lau WK, Feng HT, Li SFY. Detection of endotoxins: from inferring the responses of biological hosts to the direct chemical analysis of lipopolysaccharides. Crit Rev Anal Chem 2019;49(2):126-137. doi: 10.1080/10408347.2018.1479958.

[36] Komazin G, Maybin M, Woodard RW, Scior T, Schwudke D, Schombel $U$, et al. Substrate structure-activity relationship reveals a limited lipopolysaccharide chemotype range for intestinal alkaline phosphatase. J Biol Chem 2019;294(50):19405-19423. doi:10.1074/jbc. RA119.010836. 